\title{
As dividas em moeda estrangeira no reajustamento economico.
}

\author{
Dr. Waldemar Ferreira
}

I. O reajustamento das dividas em moeda estrangeira ajustadas no paiz.

II. O cambio da conversão da moeda estrangeira em nacional.

III. A moeda da indenização e a da divida.

IV. A moratoria decenal.

V. A taxa dos juros moratorios.

VI. $O$ intuito do reajustamento.

VII. A compra de maquinismos para beneficiamento de produtos agricolas e o reajustamento da divida dela resultante.

VIII. A hipotese do art. $20, d$ ), do dec. n. 24.233 , de 12 de maio de 1934.

\section{P A R E C E R}

1. Constituiu-se a divida de que se trata antes de 30 de março de 1930.

Resultante da compra de materiais e aparelhos para a fabricação de assucar e de alcool e respetiva distilação, consolidou-se, novando-se, por escritura publica daquela data.

Passou, mercê do ajuste, nela consignado, a representar-se por notas promissorias, naquele mesmo dia emitidas, cujas importancias, capital e juros inclusivé, por efeito de conversão de moedas, se exprimiram em francos franceses, ga- 
rantidas com hipoteca da propriedade agricola no titulo convenientemente individualisada.

Convencionou-se, no entanto, e de entrada, na aludida escritura, deverem sempre os pagamentos das importancias devidas, constantes das promissorias ser ef etuados nesta capital, ao portador do titulo ou ao representante da credora, em moeda corrente do paiz, equivalente a do titulo, ao cambio da venda para cheque, isto é, á vista sobre Paris, da vespera do dia do pagamento, de acordo com a cotação da Camara Sindical dos Corretores. Usaram os contratantes da faculdade contida no art. 947, $\S 1$, do codigo civil.

Isto posto, respondo:

2. A divida, apesar de ter sido feita em francos francese, está incluida nos beneficios do reajustamento economico, por força do disposto no art. 20, a), do decr. n. 24.233, de 12 de maio de 1934.

Não se incluem, mercê desse dispositivo, no regime daquele diploma, em verdade, "as dividas contraidas em moedas estrangeira, salvo quando ajustadas dentro do país, e nele exigiveis, devendo o valor desta ser culculado pelo cambio da data do contrato".

3. Da propria escritura de 31 de março de 1930 , e expressamente, consta:

a) QUE a divida, não obstante contraída em moeda estrangeira, foi ajustada dentro do país;

b) QUE a divida é exigivel no país, devendo sempre o pagamento ser efetuado nesta cidade e capital do Estado de São Paulo.

4. Não é possivel, consequentemente, duvida a respeito. O caso sujeito é, precisamente, o previsto pela lei, de inconfundivel clareza. 
5. Estipulou-se, na escritura, dever o cambio, para o pagamento das notas promissorias, ser calculado pela cotacão da Camara Sindical dos Corretores da vespera.

Para o efeito da obtenção do beneficio do reajustamento economico, entretanto, e para a fixação da importancia integral da divida, a moeda estrangeira deve ser convertida em moeda brasileira e o calculo feito pelo cambio da data do contrato.

E o que preceitua, com todas as letras, o art. 20 , a), do decr. n. 24.233, de 12 de maio de 1934.

\section{I I}

6. Aplica-se o dispositivo, acima referido, para o calculo da indenização a que, em consequencia do decreto do reajustamento economico, tem direito todo o credor de agricultor, por divida existente a 1 de dezembro de 1933, que reuna os requisitos mencionados no art. 11.

Não teve o decreto outro intuito.

7. Reduziu ele, todavia, e esta é circunstancia de tomo, de cincoenta por cento, nos termos de seus articulados, o valor, em 1 de dezembro de 1933, de todos os debitos de agricultores, contraidos antes de 30 de junho do mesmo ano, quando adjetivados com garantia geral.

Para a fixação daquele valor, determinou se operasse a conversão da moeda estrangeira em moeda brasileira ao cambio da data do contrato.

Se, pois para conceder ao credor a indenização, objetivou o seu credito em moeda brasileira, e a sentença, que lhe reconheceu o direito a ela ipso facto reduziu a divida a cincoenta por cento, ou seja á metade, esta somente pode ser a metade do valor em moeda brasileira. Decorre uma coisa, necessariamente, da outra. Para que continuasse o devedor 
sujeito á moeda estrangeira, indispensavel era que a sentença, adjudicataria da indenização, tivesse em vista o valor em moeda estrangeira, de modo a ordenar o pagamento da metade desta, operada, em seguida, a conversão.

Assim, porém, não é.

Para o credor alcançar a indenização, converte-se a moeda estrangeira, antes de mais nada, em moeda brasileira. Nesta moeda é que o credito passa a ser considerado. A redução á metade, consequentemente, se opera na moeda brasileira.

Torna-se a conversão definitiva tanto para o credor, quanto para o devedor. Recebendo o credor, a titulo de indenização, tantos mil réis, em apolices da Divida Publica Federal, pelo seu valor par, ao juro de $5 \%$ ao ano, do valor nominal de 1:000\$000 ou de 500\$000, cada uma - ficará necessariamente, com o direito de receber a outra metade, os outros cincoenta por cento, em moeda brasileira, do seu devedor.

\section{V}

8. Facultou o decr. n. 22.626 , de 7 de abril de 1933, aos devedores o pagamento em dez prestações anuais, iguais e continuadas, de suas dividas:

a) se garantidas com hipotecas rurais ou penhores agricolas;

b) se expressa e declaradamente contraidas para financiamento de trabalhos agricolas ou para compra de maquinismos e de utensilios destinados á agricultura, seja qual fôr a modalidade delas, desde que tenham garantia real;

c) se, num e noutro caso, "efetivamente cobertas".

Eis o texto:

“As dividas a que se refere o art. 1 , $\S 1$, in fine, , 2 , se existentes ao tempo da publicação desta lei, quando ef etivamente cobertas, poderão ser pagas em dez prestações anuais, iguais e continuadas, se assim entender o devedor". 
9. Deu a expressão "efetivamente cobertas" muito pano para mangas. Muito se duvidou do seu significado e muito se discutiu a proposito, revelando-se a variedade doutrinaria na variedade jurisprudencial.

Tornou-se inutil, de certo modo, a discussão nesse sentido, em face do decr. n. 24.233 , de 12 de maio de 1934 . Influenciado pelo principio de ficar o direito do devedor á redução de sua divida á metade de seu valor subordinado ás mesmas condições a que sujeitou o direito do credor á indenização - tal foi preceito consignado no art. 19 - concluiu, peremptoriamente, no art. 29 , $\S$ unico, por excluir a recusa da indenização pela Camara de Reajustamento Economico, nos mesmos termos, o direito do devedor á redução.

Não se compreende a indenização sem que a redução se opere: uma é consequencia natural da outra.

10. Estabelecendo esse sistema, tendente a favorecer ao devedor, sem prejudicar ao credor, adiantou-se a lei a si mesma e, no art. 11, d), entre outras condições para a concessão da indenização, impôs ao credor a de obrigar-se a dar plena quitação de toda a divida no caso de, sendo o valor da garantia inferior á metade do debito, tambem ser o restante do patrimonio do devedor inferior a cincoenta por cento do seu passivo, nele incluido o remanescente da divida reajustanda.

Exarou, como se vê, preceito mais profundo em seus efeitos. Tendo em consideração, em certos casos, o estado de insolvencia do devedor, cuidou de libera-lo, definitivamente, de suas dividas, abrindo-lhe oportunidade para uma nova fase de vida e de negocios. Desafogou-o de suas responsabilidades, cada dia maiores e mais sufocantes. Como, por outro lado, e por força das circunstancias, a situação do devedor, em tal emergencia, é realmente precaria e não menos a do credor; pela inexistencia de bens suficientes para o seu pagamento total, obrigou-o a conformar-se com ela. Deu-lhe a indenização, mas em troca da quitação plena de toda a divida. 
11. Fixou, dessarte, criterio seguro para a determinação de quais as dividas "efetivamente cobertas". Assim não se entendem quando, sendo o valor da garantia inferior á metade do valor delas, tambem o restante do patrimonio do devedor é inferior a cincoenta por cento do seu passivo, nele incluida a de que se trata.

Daí resultou o disposto no art. 38:

"Se a divida estiver no regime da moratoria decenal concedida pelo art. 10 do decr. n. 22.626, de 7 de abril de 1933, considerar-se-á a redução do presente decreto como pagamento antecipado das cinco prestações dessa moratoria, ficando o devedor obrigado apenas aos juros nas datas de tais prestações".

12. Ora, as notas promissorias de que trata a escritura de 31 de março de 1930 venceram-se, sucessivamente, em 31 de dezembro de 1930 e de 1931 , em 30 de junho e em 31 de dezembro de 1932 e em 30 de junho de 1933.

Quando, portanto, se publicou o decr. n. 22.626, de 7 de abril de 1933, uma unica existia sujeita aos seus efeitos: a ultima, a não ser que algumas das outras tivessem sido reformadas ou caissem no regime de moratoria resultante das circunstanstancias creadas pelo movimento revolucionario de 1932. De qualquer fórma as que, á data da publicação daquele decreto, ainda não haviam sido resgatadas, ficaram e estão sujeitas á moratoria decenal por ele estabelecida, em duas hipoteses:

a) na de se acharem, nos termos aqui expostos, efetivamente cobertas;

b) na de haver o devedor manifestado a sua deliberação de prevalecer-se do favor constante daquele decreto.

\section{V}

13. Na soma das notas promissorias constantes incluiram-se parte do capital, no caso do preço devido, e os juros respetivos, á taxa de $9 \%$ ao ano. 
Ficou isso escrito na clausula segunda da escriptura de 31 de março de 1930:

"A soma destas notas promissorias, aceitas pelos outorgantes corresponde, portanto, á importancia total das compras feitas, entregues e por entregar, em francos de moeda francesa, acrescida dos juros de nove por cento (9\%) ao ano, até o vencimento dos titulos".

Celebrou-se, portanto, a estipulação dos juros moratorios no contrato hipotecario.

14. Vedou, porém, o art. 1 do decr. n. 22.626, de 7 de abril de 1933, a estipulação de juros de taxas superiores á legal, ou seja a do art. 1.062 do codigo civil. Vedou-a e, para tornar mais efficiente a interdição, no art. 3 preceituou:

“As taxas de juros estabelecidas nesta lei entrarão em vigor com a sua publicação e a partir detsa data serão aplicaveis aos contratos existentes ou já ajuizados".

15. A divida, no caso vertente, proveiu da compra de materiais e aparelhos para fabricação de assucar e de alcool e para a respetiva distilação, com todos os seus pertences e accessorios.

Ficou, por conseguinte, sujeita ao disposto no art. 1, 2, daquele mesmo decreto:

"Não excederão igualmente de $6 \%$ ao ano os juros das obrigações expressa e declaradamente contraidas para financiamento de trabalhos agricolas, ou para compra de maquinismos e de utensilios destinados á agricultura, qualquer que seja a modalidade da divida, desde que tenham garantia real".

\section{VI}

16. Nem dos motivos justificantes do decreto, nem de seu texto se infere haja ele tido em vista beneficiar mais aos agricultores que contrairam dividas por compras de maquinismos ou de utensilios destinados á agricultura. Submeteu ele ao seu regime, no mesmo pé de de igualdade, tan- 
to os agricultores que se endividaram para o financiamento de trabalhos agricolas, quando os que se obrigaram em razão da compra de maquinismos e de utensilios destinados á agricultura.

\section{VII}

17. Não pode ser considerada, e não é, divida estranha á atividade agricola a compra de maquinismo para o beneficiamento de produtos agricolas, isto é, para o beneficiamento da cana e transformação dela em assucar e em alcool, como no caso em apreço.

Fazendo referencia á doutrina de J.X. CARVALHO DE $M E N D O N C G A$, escreveu o prolator deste em livro recentemente publicado:

"Assim, o engenho de cana, em que se cuide somente do plantio desta e de sua venda será uma industria agricola, em toda a extensão destes vocabulos. Não deixará de o ser pelo fato de, para melhor aproveitamento da produção, transformar-se esta em assucar, em alcool e em outros produtos. A fabricação é o meio de tirar melhor partido para a venda dos produtos agricolas e constitue acessorio da industria agricola. Se, entretanto, a empresa se dedicar ao comercio do assucar ou do alcool ou de outros produtos, constituindo a industria agricola um acessorio, transformar-se-á ela em empresa de fabrica, incluindo-se na mercancía" (Waldemar FERREIRA, Tratado de Direito Mercantil Brasileiro, vol. 1, pag. 371).

Não ha, em face da exposição, que antecede á consulta, senão como manter o que ali se manifestou.

\section{VIII}

18. Não. Não se póde, de modo algum, incluir a divida, de que se trata, entre as que, nos termos do art. 20 , d), do decr. n. 24.233, de 12 de maio de 1934, ficaram excluidas do regime do reajustamento por ele estabelecido. 
0 texto se refere, precisamente, "ás dividas expressamente constituidas para aquisição de imoveis, urbanos ou rurais"; e, na hipotese, a divida não resulta da compra de imoveis senão, e unicamente, de moveis, ou sejam maquinismos, melhor ainda, materiais e aparelhos para fabricação de assucar e de alcool e para a respetiva distilação, com todos os seus pertences e acessorios.

Imobiliza, com efeito, o art. 43, n. III, do codigo civil, considerando bens imoveis, "tudo quanto no imovel o proprietario mantiver intencionalmente empregado em sua exploração industrial, aformoseamento, ou comodidade".

Sobre ser certo, de um lado, que os materiais e aparelhos somente foram empregados e colocados na usina ou engenho depois de adquiridos, pois foram, até, comprados quando se achavam no estrangeiro e dali para aqui transportados, de modo que a divida antecedeu á imobilização intelectual, ou, melhor, á accessão intelectual, a que alude CLOVIS BEVILAQUA, no Codigo Civil Comentådo. vol. I, 3..$^{\circ}$ ed., pag. 260; de outro lado é verdade, por escrito no art. 45 do codigo civil, que os bens, de que trata o art. $43, n$. III, podem ser, em qualquer tempo, mobilizados.

Ademais, cumpre não perder de vista o preceito, tambem exarado no art. 6 da introdução do codigo civil, segun-do o qual a lei, que abre exceções a regras gerais, ou restringe direitos, só abrange os casos, que especifica.

A negativa, por tudo isso, se impõe.

São Paulo, 28 de dezembro de 1934. 